\title{
Apparent Diffusion Coefficient Can Predict Therapy Response of Hepatocellular Carcinoma to Transcatheter Arterial Chemoembolization
}

\author{
Ralph Drewes $^{\mathrm{a}}$ Constanze Heinze $^{\mathrm{a}}$ Maciej Pech ${ }^{\mathrm{a}, \mathrm{b}}$ Maciej Powerski ${ }^{\mathrm{a}}$ \\ Katja Woidacki ${ }^{c}$ Andreas Wienke ${ }^{d}$ Alexey Surov $^{a}$ Jazan Omari ${ }^{a}$ \\ aDepartment of Radiology and Nuclear Medicine, Otto-von-Guericke University, Magdeburg, Germany; ${ }^{\mathrm{b}} 2 \mathrm{nd}$ \\ Department of Radiology, Medical University of Gdansk, Gdansk, Poland; 'Section Experimental Radiology, \\ Department of Radiology and Nuclear Medicine, Otto-von-Guericke University, Magdeburg, Germany; ${ }^{d}$ Institute for \\ Medical Epidemiology, Biometrics and Informatics, Martin-Luther-University Halle Wittenberg, Halle, Germany
}

\section{Keywords \\ Hepatocellular carcinoma. Transcatheter arterial chemoembolization · Magnetic resonance imaging • Apparent diffusion coefficient - Treatment response}

\begin{abstract}
Aim: The goal of this meta-analysis was to assess the apparent diffusion coefficient (ADC) as a pre- and posttreatment (ADC value changes $[\triangle A D C]$ ) predictive imaging biomarker of response to transcatheter arterial chemoembolization (TACE) in patients with hepatocellular carcinoma (HCC). Methods: Scopus database, Embase database, and MEDLINE library were scanned for connections between pre- and posttreatment ADC values of HCC and response to TACE. Six studies qualified for inclusion. The following parameters were collected: authors, publication year, study design, number of patients, drugs for TACE, mean ADC value, standard deviation, measure method, $b$ values, and Tesla strength. The Quality Assessment of Diagnostic Studies 2 instrument was employed to check the methodological quality of each study. The meta-analysis was performed by utilizing RevMan 5.3 software. DerSimonian and Laird randomeffects models with inverse-variance were used to regard heterogeneity. The mean ADC values and 95\% confidence
\end{abstract}

intervals were computed. Results: Six studies ( $n=271$ patients with 293 HCC nodules) were included. The pretreatment mean $A D C$ in the responder group was $1.20 \times 10^{-3}$ $\mathrm{mm}^{2} / \mathrm{s}(0.98,1.42)$ and $1.14 \times 10^{-3} \mathrm{~mm}^{2} / \mathrm{s}(0.89,1.39)$ in the nonresponder group. The analysis of post-TACE $\triangle A D C$ revealed a threshold of $\geq 20 \%$ to identify treatment responders. No suitable pretreatment ADC threshold to predict therapy response or discriminate between responders and nonresponders before therapy could be discovered. Conclusion: $\triangle \mathrm{ADC}$ can facilitate early objective response evaluation through post-therapeutic ADC alterations $\geq 20 \%$. Pretreatment ADC cannot predict response to TACE.

\footnotetext{
(C) 2021 The Author(s).

Published by S. Karger AG, Basel
}

\section{Introduction}

Most hepatocellular carcinoma (HCC) patients are ineligible for curative resection at the time of diagnosis due to various reasons: multifocal HCC, vascular infiltration,

Ralph Drewes, Constanze Heinze, Alexey Surov, and Jazan Omari contributed equally to this work.

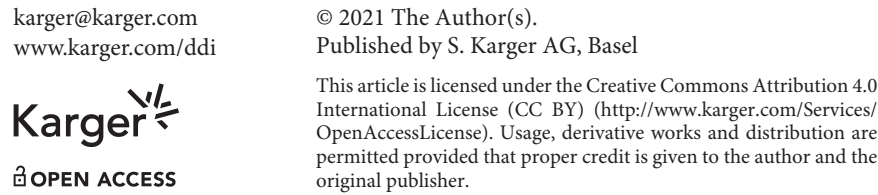

Correspondence to:

Constanze Heinze, constanze.heinze@med.ovgu.de

Alexey Surov, alexey.surov@med.ovgu.de 
impaired liver function, and extrahepatic tumor manifestations [1-6]. Transcatheter arterial chemoembolization (TACE) became an established, repeatable, stage-dependent therapy for patients unsuitable for surgery or patients awaiting transplantation (i.e., bridging). This therapy incorporates the emulsification of chemotherapeutic agents in a drug carrier and embolic material, which are injected into the tumor feeding arteries, leading to tumor necrosis and ultimately tumor regression [7]. For conventional TACE (cTACE), chemotherapeutic agents such as doxorubicin or cisplatin are blended with embolic agents (e.g., Gelfoam or polyvinyl alcohol particles) and Lipiodol that represents the drug carrier. Drug-eluting beads (DEBs) have been imposed as a novel drug carrier (polyvinyl alcohol microspheres), allowing higher concentration of the drug within the target lesion and at the same time, lower systemic concentration, facilitating similar outcomes with less toxicity than cTACE [8-12]. DEBTACE and cTACE both lead to ischemic necrosis of the target via cytotoxic and ischemic mechanisms.

Evaluation of tumor response remains paramount since lack of response would necessitate an alternative treatment approach (e.g., systemic treatment). HCCs demonstrating partial response to TACE might show a further response after repeated TACE [13]. The earliest time however to appraise HCC response to both DEBTACE and CTACE is 30-90 days after treatment as early contrast enhancement, e.g., gadolinium-enhanced magnetic resonance imaging (MRI), enables no differentiation between residual tumor and post-therapeutic inflammatory effects [14-16]. Therefore, diffusion-weighted imaging (DWI) came into play, which facilitates the detection of residual neoplastic tissue as well as necrotic areas in a timely fashion [17]. Apparent diffusion coefficient (ADC) enables quantitative assessment and the velocity of Brownian molecule movement within the interstitial space $[14,15]$, and in experimental studies, a strong inverse correlation between ADC and cell count/degree of cellularity was found $[18,19]$. However, clinical data for significant correlations between ADC and cellularity in various tumors are inconsistent; more precisely, in meta-analysis of large patient data, different inverse correlations were identified according to the tumor entity, e.g., strong correlation in gliomas, ovarian cancer, and lung cancer versus low correlation for lymphomas [20].

Several studies have evaluated DWI for HCC patients after TACE treatment [13, 17, 21-23]. Few investigators demonstrated that the mean tumor $\mathrm{ADC}$ values tend to increase after TACE corresponding to tumor necrosis $[13,21,24]$.

ADC Can Predict Response of HCC to TACE
The desire to find an earlier response assessment tool rather than a mere evaluation of size and enhancement (RECIST and mRECIST) led to further examinations of the ADC. The present meta-analysis scrutinizes ADC as a predictor of tumor response to TACE in HCC patients.

\section{Methods}

An IRB approval was not required for this meta-analysis.

\section{Data Acquisition}

MEDLINE library, Embase database, and Scopus database were scanned for connections between pretreatment ADC values of HCC and treatment response to TACE up to September 2021 (Fig. 1). The PRISMA statement was employed for research [25].

The following terms were searched: "DWI OR diffusion weighted imaging OR ADC OR apparent diffusion coefficient AND HCC OR hepatocellular carcinoma AND TACE OR transcatheter arterial chemoembolization." Secondary references were also recruited. The primary search revealed 172 results. Duplicate articles ( $n$ $=127$ ) were excluded. Abstracts of the remaining 45 articles were scrutinized. Furthermore, review articles, in vitro and experimental animal studies, case reports, and non-English publications were excluded $(n=10)$. Other articles $(n=29)$ were excluded for different reasons: mean ADC values or standard deviation not reported, no associations between ADC and treatment analyzed, or other analyses than DWI were performed.

Finally, 6 studies were eligible for the present meta-analysis [26-31]. The following data were used from the literature: authors, year of publication, number of patients, and reported ADC values of HCC in responders and nonresponders.

\section{Meta-Analysis}

In the first step, the methodological quality of the 6 included studies were checked by one observer (A.S.), applying the Quality Assessment of Diagnostic Studies instrument [32] (Fig. 2).

Afterward, the meta-analysis was done by using RevMan 5.3 (computer software, version 5.3; the Nordic Cochrane Centre, Copenhagen, Denmark, the Cochran Collaboration, 2014). Heterogeneity was computed by means of the inconsistency index $I^{2}$ [33, 34]. Last, DerSimonian and Laird [35] random-effects models with inverse-variance weights were employed without any further correction. The primary objectives were to evaluate the use of pretreatment $\mathrm{ADC}$ to predict response to TACE and $\mathrm{ADC}$ value changes $(\triangle \mathrm{ADC})$ as an indicator of response to TACE.

\section{Results}

Six studies were included in this meta-analysis [2631]. The studies come from the USA, China, and Japan and were reported between 2010 and 2020 (Table 1), where 4 studies are prospective and 2 retrospective.

All studies included patients with unresectable HCC treated with cTACE $(n=4)$ or DEB-TACE $(n=2)$. Re- 


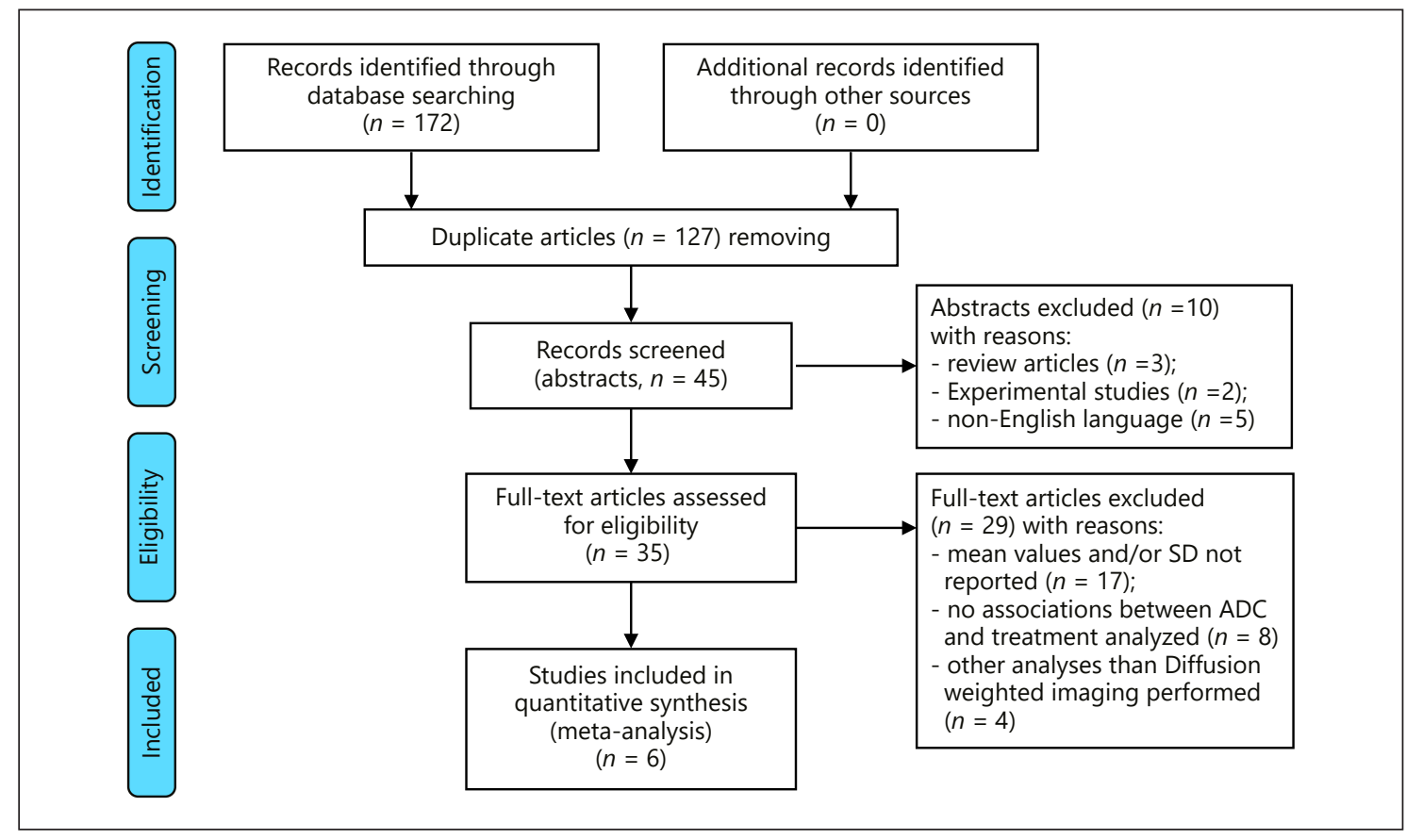

Fig. 1. PRISMA flowchart of the data acquisition. ADC, apparent diffusion coefficient; DWI, diffusion-weighted imaging.

Fig. 2. QUADAS-2 quality assessment of the included studies. QUADAS-2, Quality Assessment of Diagnostic Studies 2.

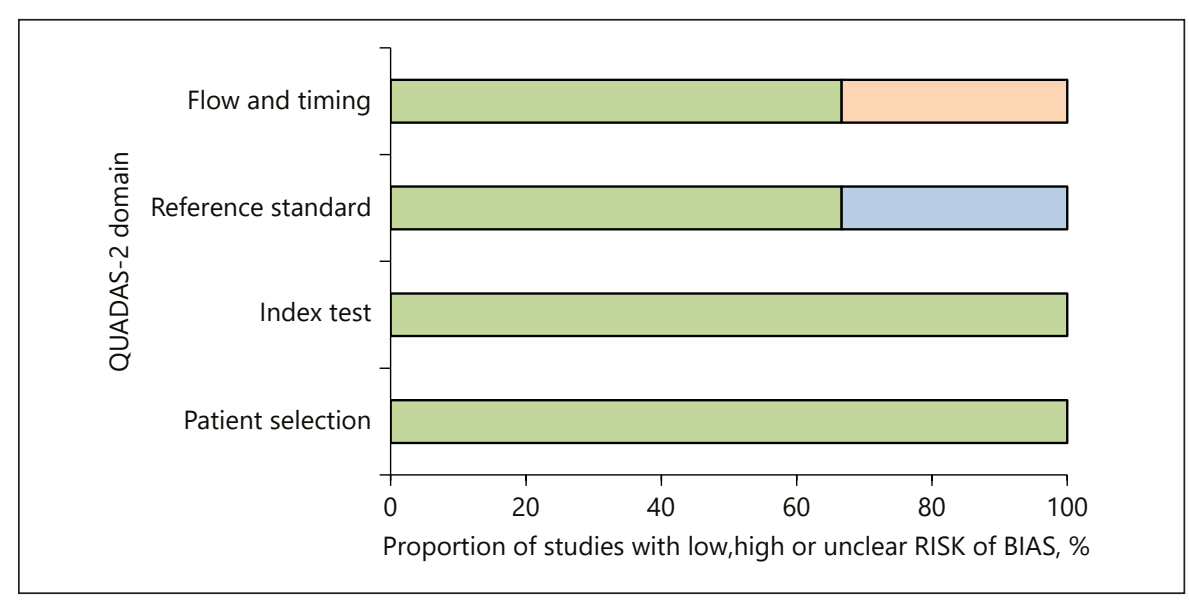

sponse assessment using dynamic contrast enhancement MRI was evaluated by WHO, RECIST 1.1, EASL, and mRECIST criteria as well as DWI. A descriptive statistical analysis including tumor distribution, ECOG performance status, Child-Pugh class, and Barcelona Clinic Liver Cancer staging was performed by Kokabi et al. [26], Ou et al. [30], and Yuan et al. [31], but the other studies lacked or did not publish this data.

Noteworthy information for the analyzed studies is listed below:
Kokabi et al. [26] concluded $\triangle \mathrm{ADC} \geq 20 \%$ has $100 \%$ sensitivity and specificity in predicting therapy response according to mRECIST and EASL at 1 and 3 months. Prediction of HCC relapse was analyzed for a $\triangle \mathrm{ADC}$ threshold of $13.6 \%$ (sensitivity $76.9 \%$ and specificity $100 \%$ ) of Kubota et al. [27].

Lin et al. [28] as well as Yuan et al. [31] included only histopathologically confirmed HCC. A maximum tumor diameter $>2 \mathrm{~cm}$ and no large necrosis were inclusion criteria for Lin et al. [28]. 
Table 1. Overview of included Studies

\begin{tabular}{|c|c|c|c|c|c|c|c|c|c|}
\hline Author & $\begin{array}{l}\text { Included number of } \\
\text { patients and etiology of } \\
\text { hepatocellular cancer, } \\
\text { HBV, and HCV }\end{array}$ & $\begin{array}{l}\text { Included } \\
\text { lesions, } n\end{array}$ & Responder & $\begin{array}{l}\text { Non- } \\
\text { responder }\end{array}$ & MR scanner & $b$ values & $\begin{array}{l}\mathrm{ADC} \\
\text { measure }\end{array}$ & $\begin{array}{l}\text { Time for } \\
\text { response/ } \\
\text { follow-up }\end{array}$ & TACE drug \\
\hline $\begin{array}{l}\text { Kokabi et al. } \\
\text { [26] }\end{array}$ & $\begin{array}{l}\text { Total, } 12 ; \mathrm{HCV}, 7 / 12 ; \\
\text { alcohol } 3 / 12 ; \mathrm{HBV}, 1 / 12 ; \\
\text { and other } 1 / 12\end{array}$ & 12 & 6 & 6 & Siemens $1.5 \mathrm{~T}$ & $\begin{array}{l}50,400 \\
800\end{array}$ & $\begin{array}{l}\text { Manual } \\
\text { ROI }\end{array}$ & $\begin{array}{l}3 \mathrm{~h}, 1 \text { and } \\
3 \text { months }\end{array}$ & $\begin{array}{l}\text { Doxorubicin } \\
\text { beads (DEB) up to } \\
100 \mathrm{mg}\end{array}$ \\
\hline Lin et al. [28] & $\begin{array}{l}\text { Total, } 118 ; \mathrm{HBV}, 66 / 118 \\
\text { no further data }\end{array}$ & 118 & 67 & 51 & No data & $\begin{array}{l}0,20,50 \\
100,200 \\
400,600 \\
800,1,000\end{array}$ & $\begin{array}{l}\text { Manual } \\
\text { ROI }\end{array}$ & 1 month & $\begin{array}{l}\text { Emulsion: } 6 \mathrm{mg} \\
\text { mitomycin: } 20 \mathrm{mg} \\
\text { Adriamycin: } 60 \\
\text { mg cisplatin: } 5-25 \\
\text { mL Lipiodol }\end{array}$ \\
\hline Ou et al. [30] & $\begin{array}{l}\text { Total, } 21 ; \mathrm{HBV}, 11 / 21 ; \\
\mathrm{HCV}, 4 / 21 ; \mathrm{HCV} \text { and } \\
\mathrm{HBV}, 4 / 21 ; \text { alcohol, } 1 / 21 ; \\
\text { and other, } 1 / 21\end{array}$ & 21 & 16 & 5 & $\begin{array}{l}\text { GE healthcare, } \\
1.5 \mathrm{~T}\end{array}$ & 0,400 & $\begin{array}{l}\text { Manual } \\
\text { ROI }\end{array}$ & $1,2,4$ weeks & $\begin{array}{l}\text { DEB vials up to } 50 \\
\mathrm{mg} \text { doxorubicin } \\
\times 2\end{array}$ \\
\hline $\begin{array}{l}\text { Yuan et al. } \\
\text { [31] }\end{array}$ & $\begin{array}{l}\text { Total, } 43 \text { and acute or } \\
\text { chronic viral hepatitis, } \\
32 / 43\end{array}$ & 59 & 36 & 23 & Philips 3 T & $\begin{array}{l}0,800 \\
1,500 \\
2,000\end{array}$ & $\begin{array}{l}\text { Manual } \\
\text { ROI }\end{array}$ & $\begin{array}{l}1 \text { month, every } \\
3 \text { months }\end{array}$ & $\begin{array}{l}1-1.5 \text { g } 5 F U, 30-40 \\
\text { mg hydroxycamp- } \\
\text { tothecin, } 40-50 \\
\text { mg Adriamycin, } \\
\text { 3-20 mL Lipiodol, } \\
\text { gelatin sponge } \\
\text { particles }\end{array}$ \\
\hline
\end{tabular}

$H B V$, hepatitis B virus; $\mathrm{HCV}$, hepatitis C virus; $A D C$, apparent diffusion coefficient; TACE, transcatheter arterial chemoembolization; $R O I$, region of interest; $D E B$, drug-eluting bead.

In the study of Mannelli et al. [29], therapy-induced necrosis, depictable in ADC post-therapy, was correlated with histopathological examinations of all transplanted patients ( 15 of 36 included patients who underwent liver transplantation at some point after TACE). An overall amount of 293 HCC lesions were treated with TACE: 182 lesions were categorized as responders and 111 as nonresponders. Only half of the studies declared the mean lesion sizes. Viral hepatitis was the underlying etiology for HCC in 160/271 patients; however, data regarding etiology is not published for 85 patients (see Table 1).

Different MRI scanners and $b$ values were used. Four studies employed a 1.5 Tesla MRI, one study a 3 Tesla MRI, and only one study by Lin et al. [28] neither gave information about the MRI manufacturer nor about Tesla strength (Table 1). DWI $b$ values were reported by all studies. The $b$ values were as follows: b50, 400, 800 (Kok- abi et al. [26]); b0, 500 (Kubota et al. [27]); b0, 20, 50, 100, 200, 400, 600, 800, 1,000 (Lin et al. [28]); b0, 50, 500 (Mannelli et al. [29]); b0, 400 (Ou et al. [30]); and b0, 800, 1,500, 2,000 (Yuan et al. [31]).

DWI was acquired by a breath-holding technique. ADC values were measured with manual whole-lesion region of interest placement.

The timeframe of MRI acquisition pre- and postTACE was heterogenous across included studies: Kokabi et al. [26] (pre: no data, post: 3 h, 1 and 3 months), Kubota et al. [27] (pre: 1-2 days, post: 5-7 days), Lin et al. [28] (pre: 1-3 days, post: 1 month), Mannelli et al. [29] (within 3 months before and after TACE), Ou et al. [30] (pre: 0-2 days, post: 1, 2 and 4 weeks), and Yuan et al. [31] (pre: no data, post: 1 month, every 3 months). The TACE drugs, which were administered to the patients, were also different (Table 1). 


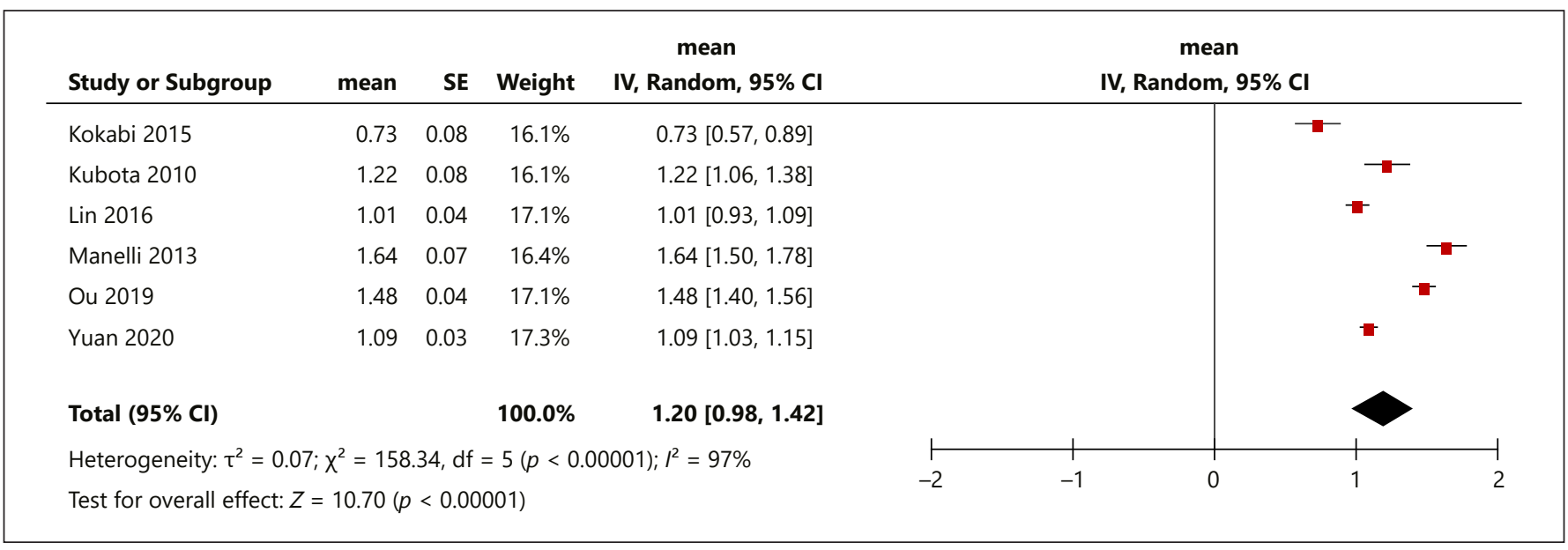

Fig. 3. Responder mean ADC, standard deviation, heterogeneity, confidence interval, and whisker plots. ADC, apparent diffusion coefficient.

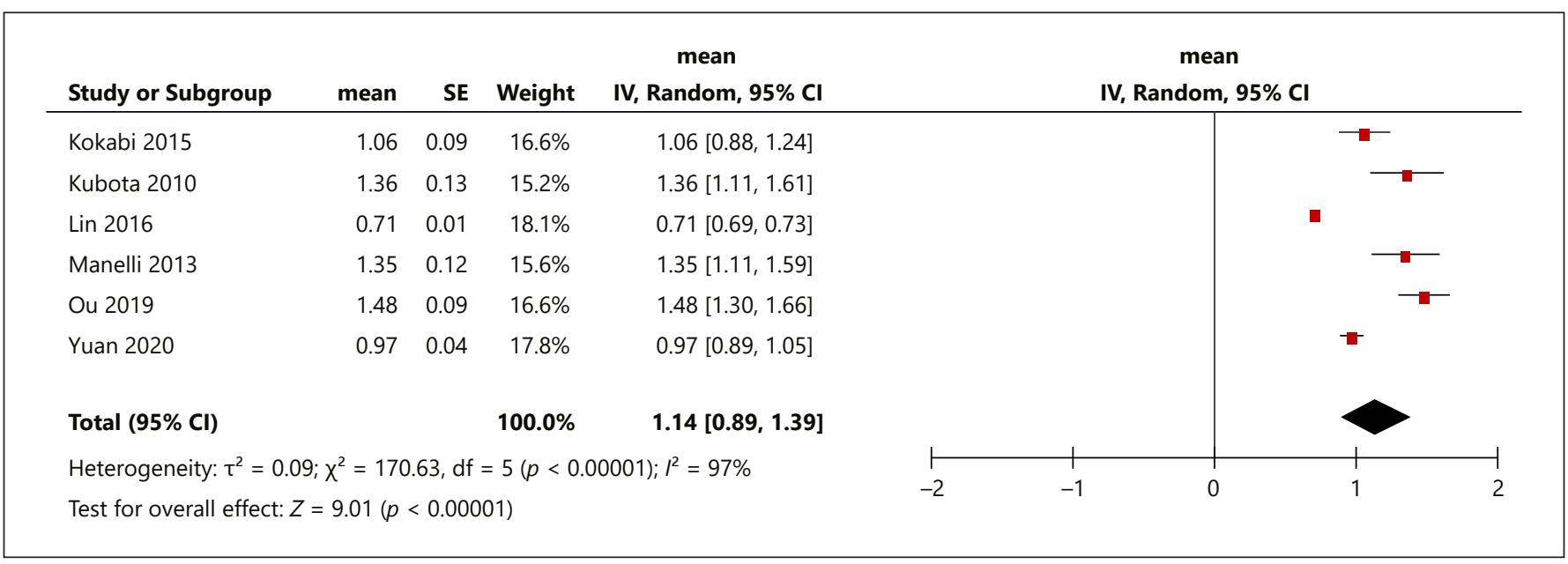

Fig. 4. Nonresponder mean ADC, standard deviation, heterogeneity, confidence interval, and whisker plots. ADC, apparent diffusion coefficient.

The pretreatment mean ADC for HCC lesions responding to TACE was $1.20 \times 10^{-3} \mathrm{~mm}^{2} / \mathrm{s}(0.98,1.42)$ and for the HCC lesions not responding to TACE $1.14 \times 10^{-3}$ $\mathrm{mm}^{2} / \mathrm{s}(0.89,1.39)$ (Fig. 3,4$)$. The box plots demonstrate the overlap between ADC values of responders and nonresponders (Fig. 5), indicating that pretreatment ADC values cannot predict treatment response to TACE.

A second analysis of posttreatment $\triangle \mathrm{ADC}$ revealed a practical threshold of $\geq 20 \%$ to identify TACE responders (Fig. 6) with a statistical outlier resulting from the ADC values of Lin et al. [28] (Table 2). The same 6 studies were eligible for this second analysis.

\section{Discussion}

This meta-analysis examines ADC values as a predictor of pathological response to transcatheter chemoembolization in HCC patients. TACE became the first choice of nonsurgical treatment $[36,37]$ for HCC patients with an intermediate Barcelona Clinic Liver Cancer stage with an estimated survival of 20 months [38]. TACE can cause some degree of ischemic liver damage as well as ischemic tumor necrosis, potentially leading to hepatic decompensation in a setting of coexisting cirrhosis $[39,40]$. DEB-TACE has significantly lowered liver 


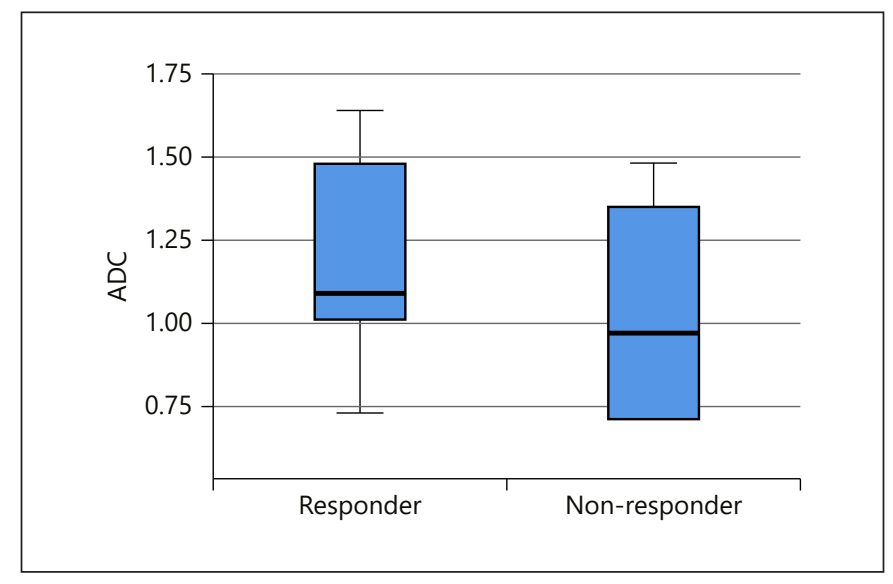

Fig. 5. ADC box plots of responders and nonresponders to TACE. ADC, apparent diffusion coefficient; TACE, transcatheter arterial chemoembolization.

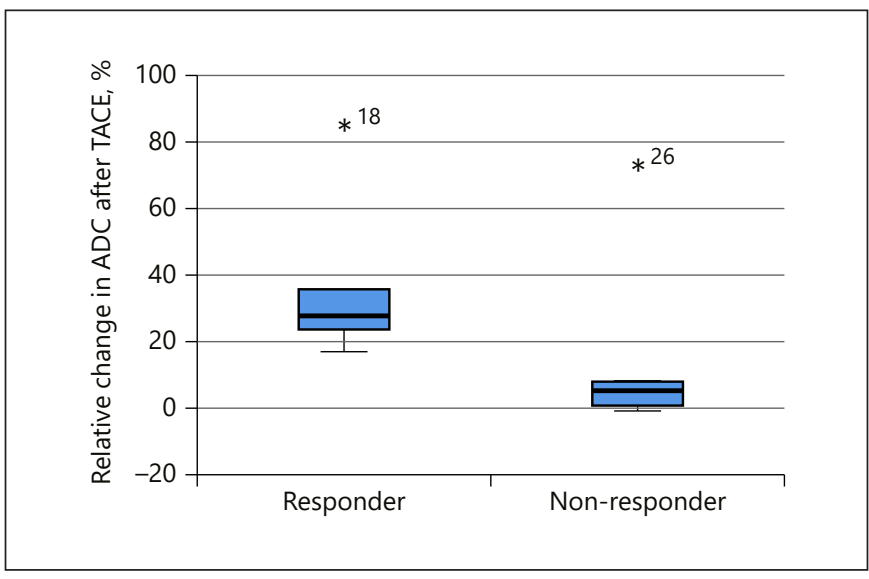

Fig. 6. $\triangle \mathrm{ADC}$ box plots of responders and nonresponders to TACE. $\triangle \mathrm{ADC}$, apparent diffusion coefficient value change; TACE, transcatheter arterial chemoembolization.
Table 2. Relative $\triangle A D C$ of responder and nonresponder lesions post-TACE

\begin{tabular}{|c|c|c|c|c|}
\hline & \multicolumn{2}{|c|}{ Responder } & \multicolumn{2}{|c|}{ Nonresponder } \\
\hline & $n(\%)$ & $\begin{array}{l}\text { relative } \\
\text { change, \% }\end{array}$ & $n(\%)$ & $\begin{array}{l}\text { relative } \\
\text { change, \% }\end{array}$ \\
\hline Kokabi et al. [26] & $6(3.3)$ & 35.6 & $6(5.4)$ & 6.6 \\
\hline Kubota et al. [27] & $23(12.6)$ & 85.2 & $13(11.7)$ & 8.0 \\
\hline Lin et al. [28] & $67(36.8)$ & 30.7 & $51(45.9)$ & 73.2 \\
\hline Mannelli et al. [29] & $34(18.7)$ & 17.1 & $13(11.7)$ & -0.7 \\
\hline Ou et al. [30] & $16(8.8)$ & 23.6 & $5(4.5)$ & 0.7 \\
\hline Yuan et al. [31] & $36(19.8)$ & 24.8 & $23(20.7)$ & 4.1 \\
\hline Summary & $182(100)$ & 33.4 & $111(100)$ & 35.7 \\
\hline
\end{tabular}

$\triangle A D C$, apparent diffusion coefficient value change; $T A C E$, transcatheter arterial chemoembolization. toxicity and systemic drug exposure than cTACE $[41$, 42].

Early objective tumor response evaluation remains a crucial aspect of any oncological treatment regime. Several authors have shown WHO and RECIST criteria to be unsuitable for HCC therapy response assessment [26]. Decrease in tumor size, measured by RECIST, lags behind changes in tumor enhancement, and ADC can take about 6 months to be measurable in response assessment.

In contrast, enhancement or necrosis-based response criteria (EASL and mRECIST) have displayed significant correlations with overall survival (OS) and progressionfree survival in HCC after TACE $[15,43]$ and are independent predictors of survival after 1 and 3 months objective response $[15,44]$. Recurrence after TACE occurs af- ter therapy-induced ischemia and a resulting upregulation of angiogenesis and VEGF expression peaking 24-36 h after embolization $[42,45]$. A decrease in contrast enhancement indicates a reduction or even interruption of tumor blood supply and correlates with necrosis and improved OS in HCC patients [23, 46, 47]. However, early enhancement patterns have clear limitations and cannot differentiate objectively between residual tumor, fibrous tumor capsule, inflammatory response (reactive edema), granulation tissue, or coagulative hemorrhagic necrosis $[15,16]$, sometimes even resulting in transiently increasing tumor diameters. High T1 pre-contrast intensity further complicates imaging interpretation.

Therefore, conclusive assessment of tumor response should be paramount before subjecting the patient to re- 
peated TACE or alternative percutaneous procedures. A more immediate and objective assessment after TACE to evaluate response, predict further treatment success, and generate or adapt a robust and cost- and side-effect-efficient therapy plan appears tempting.

The predictive power of pretreatment ADC was examined previously for colorectal cancer and gastric carcinoma liver metastases [51] [48] as well as for esophageal cancer, head and neck carcinoma, and breast cancer [49-52]. DWI sheds light on cellularity, tumor viability, tissue perfusion, and necrosis at any given time; an intact tumor cell membrane restricts water molecule diffusion (decreased ADC value) and increased permeability or lysis of the tumor cell membrane caused by tumor necrosis alleviates water molecule diffusion (higher ADC value) [53]. Hepatic cirrhosis has been demonstrated to also restrict diffusion secondary to reactive liver tissue fibrosis, leading to lowered mean ADC values for "healthy" or cancer-free hepatic tissue $[54,55]$. Another ADC influencing factor could be the dual hepatic blood supply, especially in cases of infiltrative HCC (7-15\% of all cases) with portal-vein thrombosis and a median OS of 5 months [56].

However, several studies have investigated the role of ADC in HCC; for instance, Jing et al. [57] found ADC value combined with tumor size can be used as a noninvasive method for preoperative evaluation of HCC. Besides, ADC has also been evaluated as a predictor of response to therapy, such as cisplatin-based hepatic arterial infusion chemotherapy [58] or stereotactic ablative radiotherapy [59].

The prognostic role of ADC was also investigated for various other tumors however with differing results even for the same entity: for instance, Ho et al. [60] found ADC to be a useful predictor of the outcome in cervical cancer following chemoradiation, whereas Meyer et al. [61] showed in their meta-analysis that ADC values alone were not reliable to predict therapy response to radiochemotherapy. These findings stress the need for further prospective studies taking both technical and clinical factors into consideration.

Several studies examine the application of DWI in patients treated with DEB-TACE $[41,62]$, cTACE, and radioembolization [13, 23, 24, 29, 50, 51, 62-64]. However, no consensus exists concerning ideal $b$ values, time intervals between TACE and follow-up, or MRI field strength. Kokabi et al. [26] reported significantly elevated ADC values as early as $3 \mathrm{~h}$ post-DEB-TACE in HCC patients and suggested a threshold of $20 \%$ immediately postTACE to predict responders with a $100 \%$ sensitivity and specificity. Some studies indicated that a higher percent increase in $\mathrm{ADC}$ levels after TACE predicts responder lesions and lack of recurrence [64-66], whereas ADC values of nonresponder lesions barely rise, if at all. Conflicting reports are published concerning the predictive power of pretreatment ADC values with a slight tendency toward the assumption that HCCs with lower pretreatment $\mathrm{ADC}$ values more likely respond to TACE $[26,67]$. Correspondingly, published $\mathrm{ADC}$ value thresholds predicting objective response and nonresponse vary significantly across studies. Kokabi et al. [67] reported an ADC value threshold of $0.83 \times 10^{-3} \mathrm{~mm}^{2} / \mathrm{s}$, below which an objective response can be predicted (91\% sensitivity and 96\% specificity) at 1 and 3 months after DEB chemoembolization. In contrast, different threshold were reported by Mannelli et al. [29], $0.695 \times 10^{-3} \mathrm{~mm}^{2} / \mathrm{s}$; Yuan et al. [31], $1.618 \times 10^{-3} \mathrm{~mm}^{2} / \mathrm{s}$; and Dong et al. [64], $1.3 \times 10^{-3}$ $\mathrm{mm}^{2} / \mathrm{s}$.

Lower ADC values, and thus, higher cellularity, indicate an increased cell division rate and a higher susceptibility to antineoplastic agents such as doxorubicin [67]. Viable tumor cells in rather necrotic tumor areas remain difficult to eradicate due to poor perfusion and acidic and hypoxic microenvironments, leading to limited efficacy of doxorubicin or any other antineoplastic drug [68]. Lower levels of cellularity, i.e., higher ADC values, have also been associated with diminished response to chemotherapy and ischemia-inducing therapies [62]. Unfortunately, no clear correlation between ADC values and histological tumor grading for HCC has been established yet [67]; one study showed that ADC changes are significantly associated with histopathological tumor necrosis [63].

Highly vascular $\mathrm{HCC}$ lesions, promising targets for intra-arterial therapy, are found to have lower ADC values (more restricted diffusion), whereas higher ADC levels indicate pretreatment areas of necrosis, loss of cell membrane integrity, and tumor aggressiveness [29, 31, 64]. A strong correlation was found between post-TACE ADC and necrosis based on pathology and imaging [29]. Increased ADC values post-therapy were demonstrated to be associated with cellular edema, necrosis, apoptosis, and fibrosis [69].

The analysis of HCC patients treated with TACE failed to reveal a practical pretreatment ADC threshold to predict treatment responders (Fig. 5). Responder and nonresponder ADC values show a significant overlap; hence, no general conclusion can be drawn concerning the obviously heterogenous pretreatment ADC values. Possible explanations for failure to predict response (pretreat- 
ment) are dissimilar TACE drugs and varying ADC acquisition parameters.

However, ADC values post-TACE tell a different story. An increase of at least $20 \%$ in ADC values post-TACE clearly differentiates responders and nonresponders (Fig. 6) with a statistical outlier originating from one study (Lin et al. [28], Table 2). Lin et al. [28] published neither the MRI manufacturer nor field strength and used a variety of different TACE drugs (Table 1). Ultimately, the reason for the obvious discrepancy of these results compared to the other studies remains unknown and speculative. Apart from this outlier based on one study, the $\triangle \mathrm{ADC}$ metric remains robust despite different timeframes of ADC acquisition, different drugs, and scanners. As mentioned above, Kokabi et al. [26] observed an increase of ADC values in responders as early as $3 \mathrm{~h}$ postTACE. Correspondingly, Bonekamp et al. [69] demonstrated response to TACE evaluation by increased ADC values in HCC patients.

The $b$ values were different in the studies comprised in this meta-analysis, which results inherently in different ADC mean values as well. Furthermore, ADC values acquired on unequal MRI scanners and variable field strength (1.5 and 3 Tesla) are not simply interchangeable. These factors illustrate the main concerns of some controversies concerning the use of $\mathrm{ADC}$ values as biomarkers. ADC remains a composite coefficient affected by both perfusion and diffusion. The perfusion or flow sensitivity of ADC can be reduced with choosing more than one $b$ value and a higher maximum value [63].

DWI technique, interobserver reproducibility, and reliability have been proven in several studies [70, 71]. DWI requires no administration of intravenous contrast agent and facilitates safe and comfortable examinations even for patients suffering from renal insufficiency. Clear correlations between histology and ADC values are still lacking in HCC patients but would provide a more objective insight into any factors contributing to different ADC values which are otherwise based on assumptions.

The findings of this study appear promising enough to warrant further examinations of ADC in a larger prospective study. ADC change offers a reliable and very early assessment of therapy success after TACE and facilitates efficient treatment alterations for nonresponders. Pretreatment ADC values and a predictive potential in HCC patients should be reevaluated with homogenous acquisition parameters to support or finally reject ideas of pretreatment predictions.
The present study has several limitations. Only a small number of studies met the inclusion criteria for pretreatment ADC analysis (6 studies) and delta ADC analysis (4 studies). Results in the literature form the basis of this analysis, bearing the possibility of a publication bias attributable to the general tendency to prefer and publish significant and positive results and to reject insignificant or negative ones. Some studies were excluded due to important missing metrics, e.g., standard deviation or clear group separation (responder and nonresponder).

The lack of standardized ADC acquirement and interpretation presents another major obstacle not only for HCC but also for any tumor entity. Many different variables, mostly technical MRI specifics, such as MR scanner, sequencing, $b$ values, timeframes, and biological factors, contribute to ADC values and thresholds to an unknown degree [67]. Ultimately, a uniform and clinically applicable ADC threshold might only be adopted if most or all contributing factors are standardized so that DWI can unfold its true potential as an imaging (predictive) biomarker. Obvious difficulties specific to TACE and other intra-arterial interventions concerning comparability arise due to the subjective tumor targeting through tumor blushing, sluggish flow, stasis, and variable application of the drug type and dosage.

In conclusion, a threshold of elevated ADC values $\geq 20 \%$ post-TACE might be recommended to identify responders in HCC patients; the predictive power of pretreatment $\mathrm{ADC}$ values remains uncertain due to different findings across studies and must be reevaluated in a larger prospective trial with homogenous acquisition parameters.

\section{Statement of Ethics}

An ethics statement is not applicable because this study is based exclusively on published literature.

\section{Conflict of Interest Statement}

The authors have no conflict of interest to declare.

\section{Funding Sources}

No funding was received for this article. 


\section{Author Contributions}

A.S. and A.W. conceived and designed the study; A.S., M.P., M.P., J.O., K.W., and C.H. contributed to collection and analysis of data; all the authors contributed to manuscript writing; C.H., M.P., and A.W. contributed to critical revision of the manuscript. All the authors approved the final manuscript submitted.

\section{Data Availability Statement}

All data generated or analyzed during this study are included in this article. All research data are publicly available. Further inquiries can be directed to the corresponding author.

\section{References}

1 Poon RT, Fan ST. Hepatectomy for hepatocellular carcinoma: patient selection and postoperative outcome. Liver Transpl. 2004; 10(2 Suppl 1):S39-45.

2 Song TJ, Ip EW, Fong Y. Hepatocellular carcinoma: current surgical management. Gastroenterology. 2004;127(5 Suppl 1):S248-60.

3 Minami Y, Kudo M. Imaging modalities for assessment of treatment response to nonsurgical hepatocellular carcinoma therapy: contrast-enhanced US, CT, and MRI. Liver Cancer. 2015;4(2):106-14.

4 Llovet JM, Schwartz M, Mazzaferro V. Resection and liver transplantation for hepatocellular carcinoma. Semin Liver Dis. 2005;25(2):181-200.

5 Minagawa M, Makuuchi M, Takayama T, Kokudo N. Selection criteria for repeat hepatectomy in patients with recurrent hepatocellular carcinoma. Ann Surg. 2003;238(5):703-10.

6 Lin S, Hoffmann K, Schemmer P. Treatment of hepatocellular carcinoma: a systematic review. Liver Cancer. 2012;1(3-4):144-58.

7 Pascual S, Herrera I, Irurzun J. New advances in hepatocellular carcinoma. World J Hepatol. 2016;8(9):421-38.

8 Dhanasekaran R, Kooby DA, Staley CA, Kauh JS, Khanna V, Kim HS. Comparison of conventional transarterial chemoembolization (TACE) and chemoembolization with doxorubicin drug eluting beads (DEB) for unresectable hepatocelluar carcinoma (HCC). J Surg Oncol. 2010;101(6):476-80.

9 Lammer J, Malagari K, Vogl T, Pilleul F, Denys A, Watkinson A, et al. Prospective randomized study of doxorubicin-eluting-bead embolization in the treatment of hepatocellular carcinoma: results of the PRECISION V study. Cardiovasc Intervent Radiol. 2010; 33(1):41-52.

10 Carter S, Martin Ii RC. Drug-eluting bead therapy in primary and metastatic disease of the liver. HPB. 2009;11(7):541-50.

11 Malagari K, Pomoni M, Kelekis A, Pomoni A, Dourakis S, Spyridopoulos T, et al. Prospective randomized comparison of chemoembolization with doxorubicin-eluting beads and bland embolization with BeadBlock for hepatocellular carcinoma. Cardiovasc Intervent Radiol. 2010;33(3):541-51.

12 Poon RT, Tso WK, Pang RW, Ng KK, Woo R, Tai KS, et al. A phase I/II trial of chemoembolization for hepatocellular carcinoma using a novel intra-arterial drug-eluting bead. Clin Gastroenterol Hepatol. 2007;5(9):1100-8.
13 Kamel IR, Bluemke DA, Eng J, Liapi E, Messersmith W, Reyes DK, et al. The role of functional MR imaging in the assessment of tumor response after chemoembolization in patients with hepatocellular carcinoma. J Vasc Interv Radiol. 2006;17(3):505-12.

14 European Association for the Study of the Liver. EASL clinical practice guidelines: management of hepatocellular carcinoma. J Hepatol. 2018;69(1):182-236

15 Prajapati HJ, Spivey JR, Hanish SI, El-Rayes BF, Kauh JS, Chen Z, et al. mRECIST and EASL responses at early time point by contrast-enhanced dynamic MRI predict survival in patients with unresectable hepatocellular carcinoma (HCC) treated by doxorubicin drug-eluting beads transarterial chemoembolization (DEB TACE). Ann Oncol. 2013; 24(4):965-73

16 Lim HK, Han JK. Hepatocellular carcinoma: evaluation of therapeutic response to interventional procedures. Abdom Imaging. 2002 Mar-Apr;27(2):168-79.

17 Kamel IR, Bluemke DA, Ramsey D, Abusedera $M$, Torbenson M, Eng J, et al. Role of diffusion-weighted imaging in estimating tumor necrosis after chemoembolization of hepatocellular carcinoma. AJR Am J Roentgenol. 2003;181(3):708-10.

$18 \mathrm{Xu}$ J, Does MD, Gore JC. Sensitivity of MR diffusion measurements to variations in intracellular structure: effects of nuclear size. Magn Reson Med. 2009;61(4):828-33.

19 Harkins KD, Galons JP, Secomb TW, Trouard TP. Assessment of the effects of cellular tissue properties on ADC measurements by numerical simulation of water diffusion. Magn Reson Med. 2009;62(6):1414-22.

20 Surov A, Meyer HJ, Wienke A. Correlation between apparent diffusion coefficient (ADC) and cellularity is different in several tumors: a metaanalysis. Oncotarget. 2017;8(35):59492-9.

21 Chen CY, Li CW, Kuo YT, Jaw TS, Wu DK, Jao JC, et al. Early response of hepatocellular carcinoma to transcatheter arterial chemoembolization: choline levels and MR diffusion constants - initial experience. Radiology. 2006;239(2):448-56.

22 Deng J, Virmani S, Young J, Harris K, Yang GY, Rademaker A, et al. Diffusion-weighted PROPELLER MRI for quantitative assessment of liver tumor necrotic fraction and viable tumor volume in VX2 rabbits. J Magn Reson Imaging. 2008;27(5):1069-76.
23 Mannelli L, Kim S, Hajdu CH, Babb JS, Clark TW, Taouli B. Assessment of tumor necrosis of hepatocellular carcinoma after chemoembolization: diffusion-weighted and contrastenhanced MRI with histopathologic correlation of the explanted liver. AJR Am J Roentgenol. 2009; 193(4): 1044-52.

24 Kamel IR, Liapi E, Reyes DK, Zahurak M, Bluemke DA, Geschwind JF. Unresectable hepatocellular carcinoma: serial early vascular and cellular changes after transarterial chemoembolization as detected with MR imaging. Radiology. 2009;250(2):466-73.

25 Moher D, Liberati A, Tetzlaff J, Altman DG. Preferred reporting items for systematic reviews and meta-analyses: the PRISMA statement. PLoS Med. 2009;6(7):e1000097.

26 Kokabi N, Camacho JC, Xing M, Edalat F, Mittal PK, Kim HS. Immediate post-doxorubicin drug-eluting beads chemoembolization Mr Apparent diffusion coefficient quantification predicts response in unresectable hepatocellular carcinoma: a pilot study. J Magn Reson Imaging. 2015;42(4):981-9.

27 Kubota K, Yamanishi T, Itoh S, Murata Y, Miyatake K, Yasunami H, et al. Role of diffusionweighted imaging in evaluating therapeutic efficacy after transcatheter arterial chemoembolization for hepatocellular carcinoma. Oncol Rep. 2010;24(3):727-32.

28 Lin M, Tian MM, Zhang WP, Xu L, Jin P. Predictive values of diffusion-weighted imaging and perfusion-weighted imaging in evaluating the efficacy of transcatheter arterial chemoembolization for hepatocellular carcinoma. Onco Targets Ther. 2016;9:7029-37.

29 Mannelli L, Kim S, Hajdu CH, Babb JS, Taouli B. Serial diffusion-weighted MRI in patients with hepatocellular carcinoma: prediction and assessment of response to transarterial chemoembolization. Preliminary experience. Eur J Radiol. 2013;82(4):577-82.

$30 \mathrm{Ou}$ HY, Cheng YF, Chuang YH, Hsu HW, Chen CL, Lazo MZ, et al. Quantification of functional MR predicts early response in post-doxorubicin drug-eluting beads chemoembolization for hepatocellular carcinoma. Dig Dis Sci. 2020;65(8):2433-41.

31 Yuan ZG, Wang ZY, Xia MY, Li FZ, Li Y, Shen $Z$, et al. Diffusion kurtosis imaging for assessing the therapeutic response of transcatheter arterial chemoembolization in hepatocellular carcinoma. J Cancer. 2020;11(8):2339-47.

Drewes/Heinze/Pech/Powerski/Woidacki/ Wienke/Surov/Omari 
32 Whiting PF, Rutjes AW, Westwood ME, Mallett S, Deeks JJ, Reitsma JB, et al. QUADAS-2: a revised tool for the quality assessment of diagnostic accuracy studies. Ann Intern Med. 2011;155(8):529-36.

33 Leeflang MM, Deeks JJ, Gatsonis C, Bossuyt PM. Systematic reviews of diagnostic test accuracy. Ann Intern Med. 2008;149(12):88997.

34 Zamora J, Abraira V, Muriel A, Khan K, Coomarasamy A. Meta-DiSc: a software for meta-analysis of test accuracy data. BMC Med Res Methodol. 2006;6:31.

35 DerSimonian R, Laird N. Meta-analysis in clinical trials. Control Clin Trials. 1986;7(3): $177-88$.

36 Shin SW. The current practice of transarterial chemoembolization for the treatment of hepatocellular carcinoma. Korean J Radiol. 2009 Sep-Oct;10(5):425-34.

37 Wiggermann P, Sieron D, Brosche C, Brauer T, Scheer F, Platzek I, et al. Transarterial chemoembolization of child-A hepatocellular carcinoma: drug-eluting bead TACE (DEB TACE) vs. TACE with cisplatin/lipiodol (cTACE). Med Sci Monit. 2011;17(4):CR18995.

38 Llovet JM, Bruix J. Systematic review of randomized trials for unresectable hepatocellular carcinoma: chemoembolization improves survival. Hepatology. 2003;37(2):429-42.

39 Chung JW, Park JH, Han JK, Choi BI, Han MC, Lee HS, et al. Hepatic tumors: predisposing factors for complications of transcatheter oily chemoembolization. Radiology. 1996; 198(1):33-40.

40 Chan AO, Yuen MF, Hui CK, Tso WK, Lai CL. A prospective study regarding the complications of transcatheter intraarterial lipiodol chemoembolization in patients with hepatocellular carcinoma. Cancer. 2002;94(6): 1747-52.

41 Reyes DK, Vossen JA, Kamel IR, Azad NS, Wahlin TA, Torbenson MS, et al. Single-center phase II trial of transarterial chemoembolization with drug-eluting beads for patients with unresectable hepatocellular carcinoma: initial experience in the United States. Cancer J. 2009;15(6):526-32.

42 Wang B, Xu H, Gao ZQ, Ning HF, Sun YQ, Cao GW. Increased expression of vascular endothelial growth factor in hepatocellular carcinoma after transcatheter arterial chemoembolization. Acta Radiol. 2008;49(5):523-9.

43 Lencioni R, Llovet JM. Modified RECIST (mRECIST) assessment for hepatocellular carcinoma. Semin Liver Dis. 2010;30(1):5260.

44 Llovet JM, Real MI, Montaña X, Planas R, Coll $S$, Aponte J, et al. Arterial embolisation or chemoembolisation versus symptomatic treatment in patients with unresectable hepatocellular carcinoma: a randomised controlled trial. Lancet. 2002;359(9319):1734-9.
45 Li X, Feng GS, Zheng CS, Zhuo CK, Liu X. Expression of plasma vascular endothelial growth factor in patients with hepatocellular carcinoma and effect of transcatheter arterial chemoembolization therapy on plasma vascular endothelial growth factor level. World J Gastroenterol. 2004;10(19):2878-82.

46 Kim S, Mannelli L, Hajdu CH, Babb JS, Clark TW, Hecht EM, et al. Hepatocellular carcinoma: assessment of response to transarterial chemoembolization with image subtraction. J Magn Reson Imaging. 2010;31(2):348-55.

47 Memon K, Kulik L, Lewandowski RJ, Wang E, Riaz A, Ryu RK, et al. Radiographic response to locoregional therapy in hepatocellular carcinoma predicts patient survival times. Gastroenterology. 2011;141(2):52635.e1-2.

48 Vossen JA, Buijs M, Liapi E, Eng J, Bluemke DA, Kamel IR. Receiver operating characteristic analysis of diffusion-weighted magnetic resonance imaging in differentiating hepatic hemangioma from other hypervascular liver lesions. J Comput Assist Tomogr. 2008 SepOct;32(5):750-6.

49 Amodeo S, Rosman AS, Desiato V, Hindman NM, Newman E, Berman R, et al. MRI-based apparent diffusion coefficient for predicting pathologic response of rectal cancer after neoadjuvant therapy: systematic review and meta-analysis. AJR Am J Roentgenol. 2018; 211(5):W205-16

50 Cheng B, Yu J. Predictive value of diffusionweighted MR imaging in early response to chemoradiotherapy of esophageal cancer: a meta-analysis. Dis Esophagus. 2019;32(4): doy065.

51 Chung SR, Choi YJ, Suh CH, Lee JH, Baek JH Diffusion-weighted magnetic resonance imaging for predicting response to chemoradiation therapy for head and neck squamous cell carcinoma: a systematic review. Korean J Radiol. 2019;20(4):649-61.

52 Wu LM, Hu JN, Gu HY, Hua J, Chen J, Xu JR. Can diffusion-weighted MR imaging and contrast-enhanced MR imaging precisely evaluate and predict pathological response to neoadjuvant chemotherapy in patients with breast cancer? Breast Cancer Res Treat. 2012; 135(1):17-28.

53 Li SP, Padhani AR. Tumor response assessments with diffusion and perfusion MRI. J Magn Reson Imaging. 2012;35(4):745-63.

54 Koinuma M, Ohashi I, Hanafusa K, Shibuya $\mathrm{H}$. Apparent diffusion coefficient measurements with diffusion-weighted magnetic resonance imaging for evaluation of hepatic fibrosis. J Magn Reson Imaging. 2005;22(1): 80-5.

55 Taouli B, Tolia AJ, Losada M, Babb JS, Chan ES, Bannan MA, et al. Diffusion-weighted MRI for quantification of liver fibrosis: preliminary experience. AJR Am J Roentgenol. 2007;189(4):799-806.
56 Jang ES, Yoon JH, Chung JW, Cho EJ, Yu SJ, Lee JH, et al. Survival of infiltrative hepatocellular carcinoma patients with preserved hepatic function after treatment with transarterial chemoembolization. J Cancer Res Clin Oncol. 2013;139(4):635-43.

57 Jing M, Cao Y, Zhang P, Zhang B, Lin X, Deng $\mathrm{L}$, et al. The benefit of apparent diffusion coefficient in evaluating the invasiveness of hepatocellular carcinoma. Front Oncol. 2021;11: 719480 .

58 Sung PS, Choi MH, Yang H, Lee SK, Chun HJ, Jang JW, et al. Diffusion-weighted magnetic resonance imaging in hepatocellular carcinoma as a predictor of a response to cisplatinbased hepatic arterial infusion chemotherapy. Front Oncol. 2020;10:600233.

59 Lo CH, Huang WY, Hsiang CW, Lee MS, Lin CS, Yang JF, et al. Prognostic significance of apparent diffusion coefficient in hepatocellular carcinoma patients treated with stereotactic ablative radiotherapy. Sci Rep. 2019;9(1): 14157.

60 Ho JC, Allen PK, Bhosale PR, Rauch GM, Fuller CD, Mohamed AS, et al. Diffusionweighted magnetic resonance imaging as a predictor of outcome in cervical cancer after chemoradiation. Int J Radiat Oncol Biol Phys. 2017;97(3):546-53

61 Meyer HJ, Wienke A, Surov A. Pre-treatment apparent diffusion coefficient does not predict therapy response to radiochemotherapy in cervical cancer: a systematic review and meta-analysis. Anticancer Res. 2021;41(3): 1163-70.

62 Guo Y, Yaghmai V, Salem R, Lewandowski RJ, Nikolaidis P, Larson AC, et al. Imaging tumor response following liver-directed intraarterial therapy. Abdom Imaging. 2013;38(6): 1286-99.

63 Vandecaveye V, Michielsen K, De Keyzer F, Laleman W, Komuta M, Op de beeck K, et al. Chemoembolization for hepatocellular carcinoma: 1-month response determined with apparent diffusion coefficient is an independent predictor of outcome. Radiology. 2014; 270(3):747-57.

64 Dong S, Ye XD, Yuan Z, Xu LC, Xiao XS. Relationship of apparent diffusion coefficient to survival for patients with unresectable primary hepatocellular carcinoma after chemoembolization. Eur J Radiol. 2012;81(3):472-7.

65 Sahin H, Harman M, Cinar C, Bozkaya H, Parildar M, Elmas N. Evaluation of treatment response of chemoembolization in hepatocellular carcinoma with diffusion-weighted imaging on 3.0-T MR imaging. J Vasc Interv Radiol. 2012;23(2):241-7.

66 Goshima S, Kanematsu M, Kondo H, Yokoyama R, Tsuge Y, Shiratori Y, et al. Evaluating local hepatocellular carcinoma recurrence post-transcatheter arterial chemoembolization: is diffusion-weighted MRI reliable as an indicator? J Magn Reson Imaging. 2008;27(4): 834-9. 
67 Kokabi N, Ludwig JM, Camacho JC, Xing D, Mittal PK, Kim HS. Baseline and Early MR Apparent Diffusion Coefficient Quantification as a Predictor of Response of Unresectable Hepatocellular Carcinoma to Doxorubicin Drug-Eluting Bead Chemoembolization. J Casc Intern Radiol. 2015;26(12):1777-86.

68 Deng J, Miller FH, Rhee TK, Sato KT, Mulcahy MF, Kulik LM, et al. Diffusion-weighted MR imaging for determination of hepatocellular carcinoma response to yttrium-90 radioembolization. J Vasc Interv Radiol. 2006; 17(7):1195-200.
69 Bonekamp S, Li Z, Geschwind J-FH, Halappa VG, Corona-Villalobos CP, Reyes D, et al. Unresectable hepatocellular carcinoma: MR imaging after intraarterial therapy. Part I. Identification and validation of volumetric functional response criteria. Radiology. 2013; 268(2):420-30.
70 Koh DM, Collins DJ. Diffusion-weighted MRI in the body: applications and challenges in oncology. AJR Am J Roentgenol. 2007; 188(6):1622-35

71 Lambregts DM, Maas M, Riedl RG, Bakers FC, Verwoerd JL, Kessels AG, et al. Value of ADC measurements for nodal staging after chemoradiation in locally advanced rectal cancer-a per lesion validation study. Eur Radiol. 2011;21(2):265-73. 